\title{
A Política Monetária do Banco Central durante a Presidência de Henrique Meirelles
}

\section{The Monetary Policy of the Brazilian Central Bank under the Presidency of Henrique Meirelles}

Resumo: Este artigo estima uma regra de Taylor para o período 2003-2010, quando o Banco Central foi presidido por Henrique Meirelles. Ao contrário de estudos anteriores, a frequência dos dados utilizados tem como base as reuniões do Comitê de Política Monetária (Copom), refletindo melhor o conjunto de informações disponível para a autoridade monetária. Os resultados apontam que sob a presidência de Henrique Meirelles, o regime de metas para a inflação foi conduzido de forma estrita, reagindo fortemente aos desvios das expectativas de inflação em relação à meta, mas também dando atenção para o comportamento do produto na condução na política monetária.

Palavras-chave: Política monetária. Taxa de juros. Regra de Taylor.

Abstract: This paper estimates a Taylor Rule for the period 2003-2010, when Henrique Meirelles was the chairman of Brazilian Central Bank. In contrast with previous research, data frequency is based on Monetary Policy Committee meetings (COPOM), better reflecting the information set available for the monetary authority. The results indicate a strict inflation target behavior, with strong response to inflation expectations, and a minor but relevant role for the output gap for monetary policy decisions.

Keywords: Monetary policy. Interest rate. Taylor Rule.

JEL Classification: E43; E58; E52.

\section{1 lntrodução}

Em qualquer regime monetário com algum grau de discricionariedade, as decisões de política monetária levam em consideração um grande conjunto de

Doutorando em Economia pela Universidade de Brasília (UnB). E-mail: adoniasevaristo@hotmail.com 
informações sobre a economia, como dados de atividade econômica, inflação corrente e esperada, condições financeiras, preços de commodities e ativos financeiros, inclusive a taxa de câmbio. Tendo em vista a gama de variáveis envolvidas, o estudo de funções de reação sempre atraiu a atenção dos pesquisadores, por permitir que os movimentos na taxa básica da economia sejam explicados por poucas variáveis.

O objetivo deste artigo é verificar como foi a condução da política monetária sob a presidência de Henrique Meirelles, o mais longevo de todos os presidentes do Banco Central. No intuito de responder a essa questão, neste artigo são estimadas funções de reação levando em consideração os dados efetivamente disponíveis nas reuniões do Comitê de Política Monetária (Copom) do Banco Central do Brasil. Como, a partir de 2006, as reuniões do Copom passaram a ser realizadas oito vezes ao ano, em vez de mensalmente, estimações de regras de Taylor que utilizam dados mensais para todo o período podem não conseguir capturar adequadamente as variáveis disponíveis para a tomada de decisão da autoridade monetária. Nesse sentido, a frequência dos dados utilizados tomou como base as datas das reuniões do Copom, de modo a melhor refletir o conjunto de informações disponível para a autoridade monetária.

Vale notar que a atribuição da política monetária do período ao presidente Henrique Meirelles, neste trabalho, tem um propósito apenas simplificador, uma vez que as decisões são tomadas atrás do Comitê de Política Monetária (Copom), em que cada membro tem poder de voto. Contudo, o presidente tem o voto de qualidade. ${ }^{1}$

Os estudos sobre a regra de Taylor são extensos, tendo em vista sua simplicidade e a boa aderência aos dados, tendo se iniciado com a especificação inicial de Taylor (1993), considerando uma versão backward-looking, com parâmetros não estimados para o peso do hiato do produto e da inflação. No âmbito externo, Clarida, Galí e Gertler (1998) pesquisaram as respostas das autoridades monetárias de diversos países desenvolvidos, tomando como base estimações da regra de Taylor por meio do método GMM e considerando uma versão forward-looking.

No Brasil, Barcellos Neto e Portugal (2007), em estudo de natureza similar, não encontraram efeitos significativos da taxa de câmbio sobre o processo decisório de política monetária sob a presidência de Armínio, e influência moderada sob Meirelles, sendo estatisticamente significante nos modelos estimados, mas com coeficientes de pequena magnitude.

Soares e Barbosa (2006) estimaram regras de Taylor para o período compreendido entre 1999 e 2005, permitindo variabilidade tanto na taxa de juros real a longo prazo quanto na meta de inflação. Para a taxa de juros real variável no tempo, foi considerada a soma da taxa de juro real americana com o risco-país

Disponível em: <http://www.bcb.gov.br/?COPOMHIST > Acesso em: 18 jun. 2013. 
do Brasil. Os autores utilizaram dados mensais, tendo sido utilizado o método de mínimos quadrados em dois estágios. O resultado dos modelos estimados aponta para as seguintes variáveis como relevantes para a determinação da taxa de juros: a taxa de juros defasada, o desvio das expectativas de inflação da meta, o hiato do produto e o câmbio real.

Sulzbach (2009) tomou como base os dados de 2000 a 2009 e concluiu que, sob a presidência de Meirelles, o peso atribuído às expectativas de inflação se reduziu. Em relação ao hiato do produto, o seu coeficiente passa a ser não significativo, não sendo possível distinguir alteração significativa no peso atribuído à atividade econômica entre uma presidência e outra.

Salgado, Garcia e Medeiros (2005) estimaram uma função de reação não linear para após a implantação do Plano Real, abrangendo os anos de 1994 a 2000. A variação das reservas internacionais é relevante para explicar as variações na taxa Selic, particularmente durante períodos de crise financeira, de modo que nesses períodos o foco da política monetária foi evitar a fuga de capitais. Uma especificação similar, também incluindo a variação das reservas cambiais na função de reação da autoridade monetária, foi adotada no estudo de Carneiro e Wu (2001).

Magalhães (2007) estimou regras de Taylor com parâmetros variáveis no tempo, com frequência trimestral, e encontrou que, na maior parte do período de metas para a inflação, a resposta da autoridade monetária aos desvios na expectativa de inflação foi bastante elevada, e superior à taxa de juros real, concluindo que a política monetária do Banco Central foi estabilizadora no período em consideração.

Gonçalves e Fenolio (2007) investigaram se existem influências do ciclo eleitoral na condução da política monetária, utilizando estimações da regra de Taylor com a inclusão de dummies eleitorais. Tanto por meio de $\mathrm{MQO}$, quanto por meio de GMM, os resultados encontrados mostram um aumento na aversão inflacionária do Banco Central no período de 2003 a 2006, representado pelo aumento do coeficiente da variável de desvio das expectativas de inflação em relação à meta, além de um coeficiente positivo e estatisticamente significante para o hiato do produto.

Abrangendo os primeiros anos do regime de metas para a inflação, Minella et al. (2003) encontraram um coeficiente negativo para o hiato do produto, interpretando o resultado como decorrência de choques de oferta que atingiram a economia brasileira no início dos anos 2000. Ademais, o coeficiente estimado para as expectativas de inflação se mostra positivo, estatisticamente significante e superior à unidade. Em conjunto, os autores concluem que houve uma acentuada resposta do Banco Central às expectativas de inflação no período.

Holland (2005) analisou a possibilidade de o Banco Central reagir mais às variações cambiais do que à inflação, o que decorreria do fear of floating nos países 
emergentes. Por meio de funções de reação para o regime de metas para a inflação até 2005, o autor conclui pela reação da autoridade monetária às variações no câmbio nominal, mas não ao câmbio real.

Abrangendo um período maior, Modenesi (2010) estimou uma função de Taylor backward-looking para o Banco Central, encontrando um elevado grau de suavização de juros $(0,92)$, além de encontrar um coeficiente positivo e estatisticamente significante para o hiato do produto $(0,33)$, o que não havia ocorrido em muitos trabalhos anteriores para o Brasil.

Caetano, Silva Jr. e Correa (2011) desenvolveram modelos para o processo decisório da taxa Selic (redução, estabilidade ou elevação) com base em modelos discretos, em contraste com a abordagem contínua utilizada por outros autores. Dependendo da especificação, os modelos criados têm como variáveis explicativas o desvio das expectativas de inflação 12 meses à frente em relação à meta de inflação, o índice de confiança do consumidor e a taxa Selic defasada, o superávit primário do setor público como proporção do PIB e o emprego formal. Os modelos desenvolvidos possuem boa capacidade preditiva, com grau de acerto variando entre 74 e $83 \%$ das reuniões.

Além desta introdução, este artigo está organizado da seguinte forma: a seção 2 apresenta os dados utilizados e o modelo estimado; a seção 3 discute e apresenta os resultados; e a seção 4 conclui. $\mathrm{O}$ apêndice mostra um exercício de robustez dos resultados.

\section{Metodologia e Descrição dos Dados}

O modelo estimado é o padrão na literatura para dados mensais:

$$
i_{t}=\alpha_{1} i_{t-1}+\alpha_{2} i_{t-2}+\left(1-\alpha_{1}-\alpha_{2}\right)\left(\alpha_{3}+\alpha_{4}\left(\mathrm{E}_{t} \pi_{t+j}-\pi_{t+j}^{*}\right)+\alpha_{5} y_{t-2}+\alpha_{6} \Delta q_{t}\right)
$$

Conforme mencionado na introdução, uma importante diferença desta pesquisa em relação às anteriores reside na frequência dos dados utilizados. Enquanto a maioria dos estudos utiliza a frequência mensal ou trimestral para o Brasil, os dados utilizados neste artigo tomam como base o espaçamento entre cada reunião do Copom. Desse modo, a amostra é formada por 76 observações, tendo início na primeira reunião do Copom em 2003 (no dia 22 de janeiro) e se encerrando em 2010 (na reunião do dia 8 de dezembro). Essa abordagem para a frequência a ser utilizada nas estimações pretende representar melhor o conjunto de informações disponível para a tomada de decisão da autoridade monetária. Uma razão adicional é que a partir de 2006 as reuniões do Copom passaram a ser realizadas 8 vezes ao ano. Dessa forma, pesquisas que utilizam dados mensais a partir de 2006 podem não capturar essa característica. 
Segue uma descrição das variáveis utilizadas:

a) $i_{t}$ é a meta para a taxa Selic, fixada pelo Banco Central na reunião t;

b) $i_{t-1}$ e $i_{t-2}$ : taxa Selic fixada pelo Banco Central na reunião anterior ( $\left.\mathrm{t}-1\right) \mathrm{e}$ na reunião que precedeu a reunião anterior ( $\mathrm{t}-2)$. Essas variáveis foram utilizadas para levar em consideração a característica de suavização da taxa de juros. O segundo termo defasado foi utilizado para eliminar a presença de autocorrelação serial nas estimações, que ocorria mesmo quando o primeiro termo defasado estava presente;

c) $\mathrm{E}_{t} \pi_{t+j}-\pi^{*}{ }_{t+j}$ : desvio das expectativas de inflação da meta, apurado na data da reunião do Copom, ou no dia imediatamente anterior. Essa variável foi construída conforme a metodologia empregada em Minella et al. (2003). ${ }^{2}$ Vale notar que como para essa variável foram utilizadas as expectativas de inflação disponíveis no dia da reunião do Copom ou no dia imediatamente anterior, seu valor não é afetado pela decisão de taxa de juros, dado que o resultado da decisão é divulgado somente no período da noite. Dessa maneira, a expectativa de inflação em $t$ não reflete a decisão de taxa de juros realizada em $t$, de forma que a expectativa de inflação pode ser considerada como uma variável predeterminada;

d) $y_{t-2}$ : hiato do produto, mensurado pela média móvel trimestral da série de produção industrial dessazonalizada, subtraída de sua tendência, tendo sido considerado para tal o filtro HP. O principal motivo para a utilização da média móvel de três meses, ao invés dos dados mensais, reside na comunicação do Banco Central, em que essa medida costuma ser mencionada mais frequentemente, por ser menos volátil e sugerir de forma mais precisa a tendência, o que pode não ocorrer com os dados mensais, mais sujeitos a acontecimentos não recorrentes. Dado a ênfase dessa medida de atividade econômica nos comunicados da autoridade monetária, o passo natural foi considerar essa série em sua função de reação. A defasagem em dois meses advém da forma como esse indicador é divulgado no Brasil. Para uma reunião do Copom no mês $t$, apenas os dados referentes ao mês t-2 estão disponíveis;

e) $\Delta \mathrm{q}_{\mathrm{t}}$ : variação percentual do índice da taxa de câmbio real efetiva entre o real e o dólar ocorrida desde a reunião anterior do Copom, ou seja,

Consiste em uma média ponderada dos desvios das expectativas de inflação do ano corrente e do próximo ano. A intuição é de que, com a proximidade do fim de um determinado ano, o Banco Central passa a dar maior importância para as expectativas do próximo ano. A fórmula para o cálculo é: $D_{j}=\frac{(12-j)}{12}\left(\mathrm{E}_{j} \pi_{t}-\pi^{*}{ }_{t}\right)+\frac{j}{12}\left(\mathrm{E}_{j} \pi_{t+1}-\pi_{t+1}^{*}\right)$, onde $j$ se refere ao mês e $t$ se refere ao ano. 
entre as reuniões t-1 e t. ${ }^{3}$ Como a série utilizada tem frequência mensal, utilizou-se a variação percentual do índice entre os meses de cada reunião;

f) $\alpha_{3}$ : a constante representa a taxa de juros (nominal) a longo prazo.

Todas as séries históricas foram extraídas do sítio do Banco Central. ${ }^{4}$ A Tabela 1 mostra a média e o coeficiente de variação das variáveis utilizadas.

Tabela 1 - Estatísticas descritivas

\begin{tabular}{cccccc}
\hline Período & Estatística & Selic & Expectativas & Hiato & $\begin{array}{c}\text { Variação } \\
\text { cambial }\end{array}$ \\
\hline \multirow{2}{*}{ Meirelles } & Média & 15,52 & 0,51 & 0,03 & $-1,65$ \\
& $\begin{array}{c}\text { Coeficiente de } \\
\text { variação }\end{array}$ & 0,31 & 1,79 & 109,07 & $-3,37$ \\
\hline
\end{tabular}

Fonte: Elaboração própria.

Os Gráficos 1, 2 e 3 mostram a evolução da taxa Selic em conjunto com as demais variáveis consideradas.

Gráfico 1 - Evolução da taxa Selic e da variação cambial entre reuniões do Copom

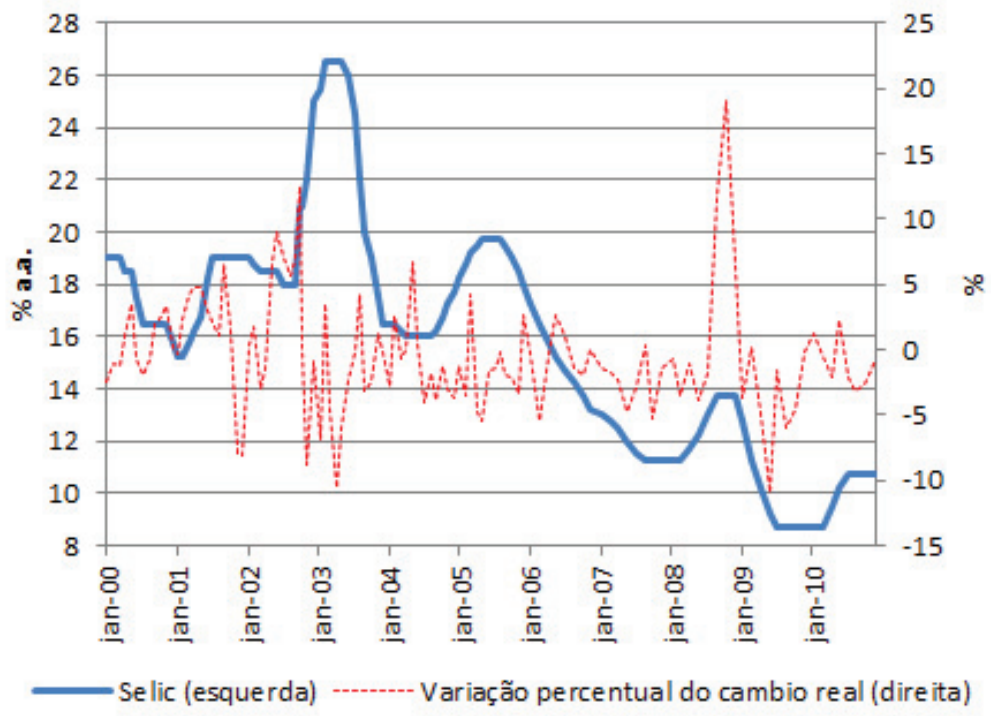

Fonte: Elaboração própria.

3 Agradeço os comentários de um parecerista anônimo, que recomendou a utilização dessa variável. A série utilizada é a de número 11.758 do conjunto de séries temporais disponibilizadas pelo Banco Central, que é deflacionada pelo IPA-DI. Como teste de robustez, apresentado no Apêndice A, também foi utilizada a variação percentual do índice da taxa de câmbio real efetiva entre o real e o dólar deflacionado pelo IPCA (série temporal de número 11.753 do BC).

4 Disponível em: <http://www.bcb.gov.br/?serietemp>. Acesso em: 18 jun. 2013. 
Para as expectativas de inflação, conforme mencionado, a medida adotada neste trabalho foi a sugerida por Minella et al. (2003), que consiste em uma ponderação dos desvios das expectativas de inflação do ano corrente e do próximo ano. Entretanto, o Gráfico 2 apresenta também outra medida da ancoragem das expectativas de inflação, que consiste em subtrair das expectativas de inflação para os próximos 12 meses a meta de 4,5\% a.a. Essa medida foi sugerida e empregada no estudo de Soares e Barbosa (2006). Nota-se que as duas séries de desvio das expectativas de inflação têm uma dinâmica bastante semelhante.

Nota-se que as duas séries tem um movimento bastante similar, com a taxa Selic acompanhando de forma bem próxima as expectativas de inflação. Somente a partir de 2009, quando as expectativas de inflação voltam a se elevar em relação à meta, é possível observar uma defasagem um pouco maior na resposta da taxa Selic, que volta a se elevar em abril de 2010.

Gráfico 2 - Evolução da taxa Selic e do desvio das expectativas de inflação

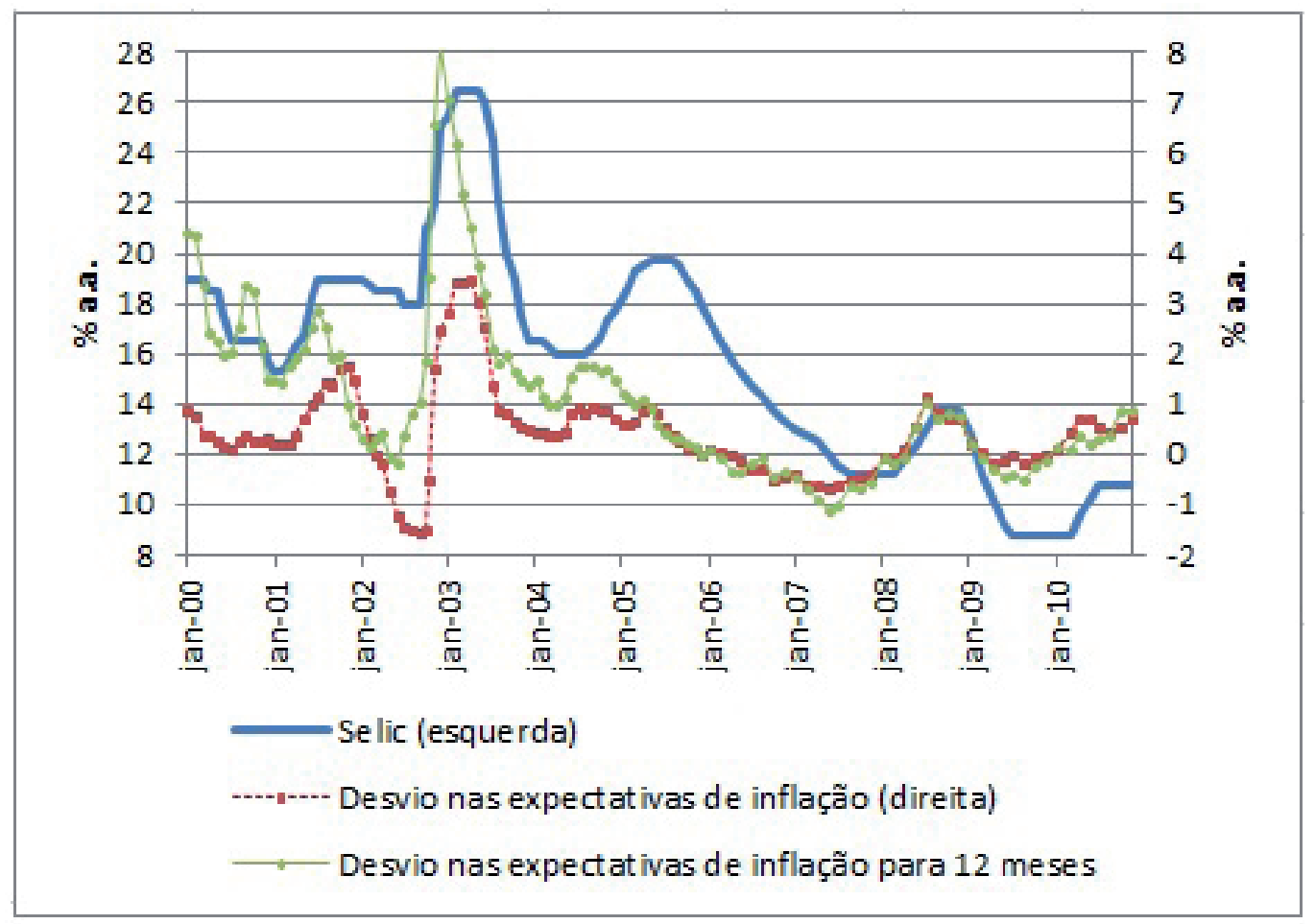

Fonte: Elaboração própria.

De forma análoga ao desvio das expectativas de inflação, no Gráfico 3, que apresenta a evolução da taxa Selic com o hiato do produto, essa variável está calculada com base em duas medidas. A primeira toma como base o filtro HP, ao passo que a segunda considera os resíduos de uma regressão da média móvel de três meses da produção industrial dessazonalizada em uma constante e com tendência linear. A evolução de ambas as séries é bastante parecida ao longo dos anos. 
Dois episódios são mais nítidos no Gráfico 3. O primeiro se refere à passagem de ano de 2002 para 2003, quando da sucessão presidencial, em que o hiato do produto estava positivo, tendo coincidido com um ciclo de alta da Selic. O segundo episódio, mais recente, foi em resposta à crise de 2008, quando o hiato do produto ficou negativo, com a política monetária sendo afrouxada, até a taxa Selic alcançar o nível de $8,75 \%$ a.a.

Gráfico 3 - Evolução da taxa Selic e do hiato do produto

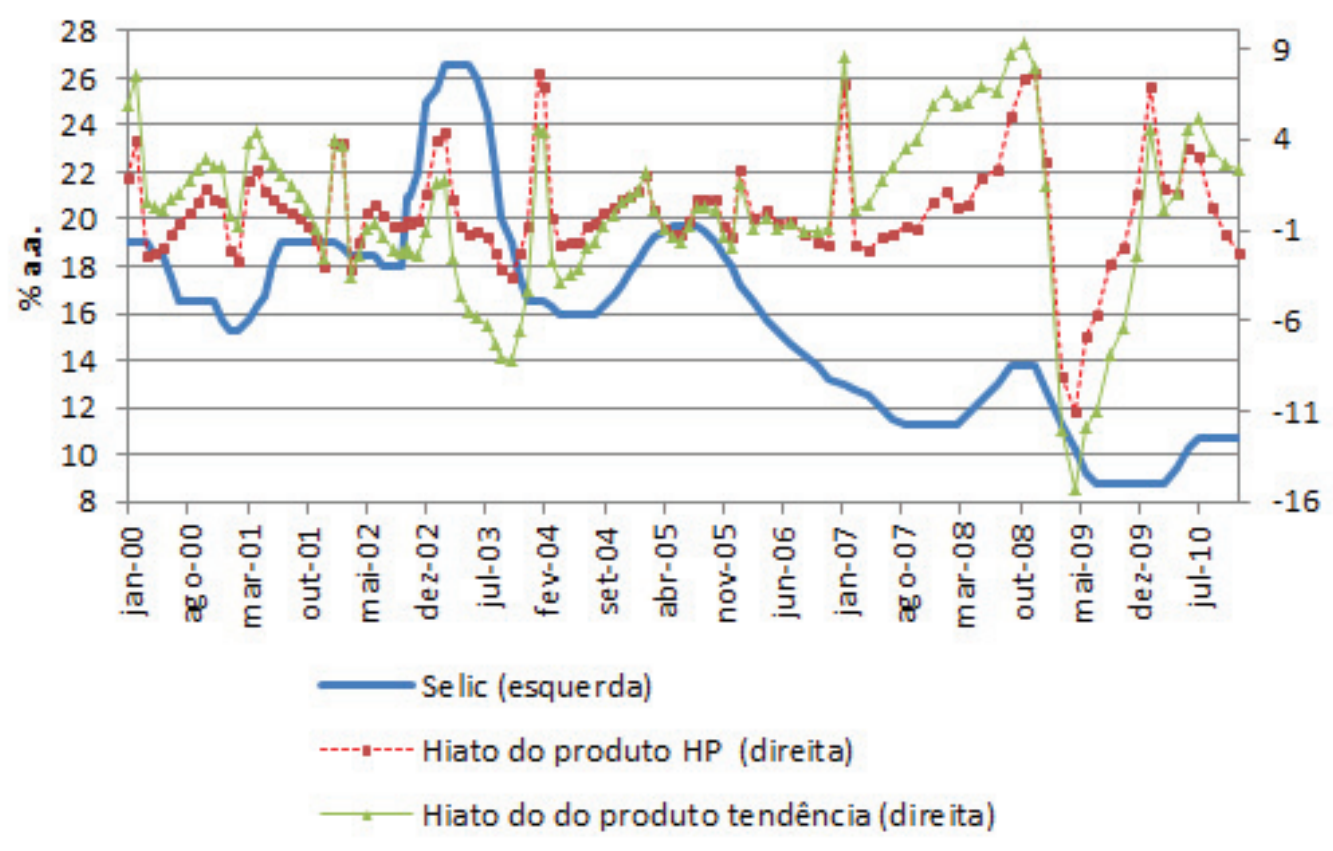

Fonte: Elaboração própria.

\section{Resultados}

Os resultados dos modelos estimados estão apresentados na Tabela 2. Os modelos foram estimados por meio de mínimos quadrados não lineares, com erros padrões robustos à heterocedasticidade.

Os resultados da primeira coluna mostram uma forte reação da autoridade monetária às expectativas de inflação durante todo o período, com o coeficiente referente ao desvio das expectativas de inflação da meta sendo superior a 6. Esse coeficiente se reduz para 4 quando adicionamos um segundo termo para a suavização da taxa de juros, mas mesmo assim continua bastante superior à unidade, de forma que podemos concluir que a política monetária foi estabilizadora durante $\mathrm{o}$ período considerado.

Adicionalmente, o coeficiente do hiato do produto é positivo e estatisticamente significante, sugerindo que a autoridade monetária também levou em consideração a atividade econômica para a definição da taxa básica de juros. O 
coeficiente o hiato do produto utilizando uma tendência linear ao invés do filtro HP é bastante semelhante ao apresentado na Tabela 2 e também estatisticamente significante $(0,65$, com $t=2,02$ para o modelo III), de forma que para duas medidas do hiato do produto temos o resultado de que a autoridade deu peso para a atividade no processo decisório da taxa Selic entre 2003 e 2010.

Por sua vez, os resultados não indicam uma resposta da autoridade monetária às variações cambiais entre cada reunião, com o coeficiente estimado negativo, mas sem significância estatística.

Tabela 2 - Estimações para 2003-2010. Variável dependente: Taxa Selic (meta)

\begin{tabular}{cccc}
\hline Variável explicativa & (I) & (II) & (III) \\
\hline Constante & $9.99^{* * *}$ & $11.31^{* * *}$ & $11.11^{* * *}$ \\
& $(10.96)$ & $(11.21)$ & $(10.61)$ \\
Selic (t-1) & $0.92^{* * *}$ & $1.39^{* * *}$ & $1.39^{* * *}$ \\
& $(56.80)$ & $(10.48)$ & $(10.33)$ \\
Selic (t-2) & & $-0.45^{* * *}$ & $-0.44^{* * *}$ \\
& & $(-3.5)$ & $(-3.45)$ \\
Desvio das & & & \\
expectativas & $6.71^{* * *}$ & $4.53^{* * *}$ & $4.54^{* * *}$ \\
& $(7.17)$ & $(3.93)$ & $(3.8)$ \\
Hiato do produto & $0.89^{* * *}$ & & $0.61^{* *}$ \\
& $(3.89)$ & $0.56^{* *}$ & $(2.62)$ \\
Variação cambial & & $(2.40)$ & -0.14 \\
& & & $(-0.51)$ \\
R2 & & & 0.99 \\
N & 0.99 & 0.99 & 76 \\
Res. Dev. & & 76 & 52.64 \\
Root MSE & 0.42 & 0.35 & 0.35 \\
\hline
\end{tabular}

Fonte: Elaboração própria.

Nota: Estatística $t$ entre parênteses. * " * $\mathrm{e}$ *** indicam coeficientes estatisticamente significantes a 10,5 e $1 \%$, respectivamente.

Um aspecto relevante dos modelos estimados é o elevado coeficiente de suavização da taxa de juros no período, oscilando entre 0,92 (modelo I) e 0,94 (modelo II). A adição da variação do câmbio real na função de reação não ajuda na explicação da evolução da taxa de juros no período. 
A constante, que é o coeficiente da taxa de juros nominal a longo prazo, tem seu valor estimado variando entre $10 \%$ e $11 \%$ a.a. Levando-se em consideração uma meta de inflação de $4,5 \%$ a.a., vigente desde 2005 , a taxa de juros real implícita ficaria em torno de $6 \%$ a.a.

O Gráfico 4 mostra a taxa de juros real trimestral, calculada por meio da média trimestral da taxa Selic efetiva anualizada e deflacionada pela taxa de inflação do IPCA de cada trimestre. Percebe-se claramente uma queda ao longo do tempo. Até o segundo trimestre de 2006, a taxa de juros real oscilou em torno de 15\% a.a., sendo posteriormente paulatinamente reduzida, oscilando em torno de $8 \%$ a $10 \%$ a.a. a partir do terceiro trimestre de 2007.

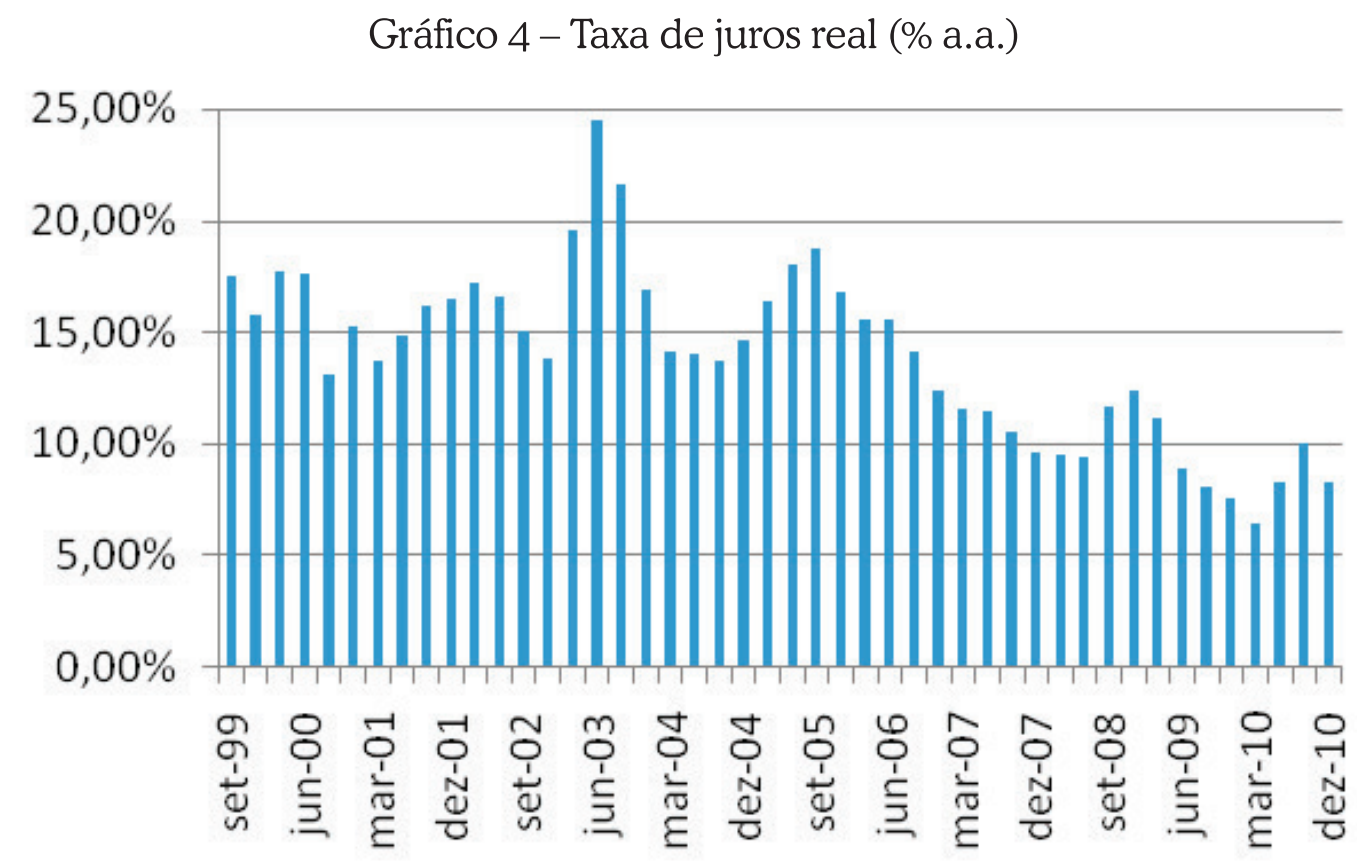

Fonte: Elaboração própria.

\section{Considerações Finais}

Esta pesquisa apresenta algumas contribuições à literatura sobre a regra de Taylor no Brasil. Em primeiro lugar, estimou uma função de reação do Banco Central sob a presidência de Henrique Meirelles. Os resultados mostram uma forte resposta da autoridade monetária aos desvios das expectativas de inflação, com coeficiente estimado superior a 4, mostrando que a política monetária foi estabilizadora no período, no sentido de que dado um aumento da taxa de inflação, a política monetária respondeu mais do que proporcionalmente, provocando um aumento dos juros reais.

A atividade econômica, aproximada pela produção industrial, parece ter tido um papel relevante na condução da política monetária, ao contrário dos re- 
sultados obtidos por outros estudos para o Brasil. Por último, a variação do câmbio real não parece ter sido determinante para as decisões da taxa Selic.

Uma segunda contribuição deste artigo se refere à base de dados utilizada. Enquanto os estudos anteriores sobre o assunto utilizaram dados mensais ou trimestrais, a frequência dos dados utilizados nesta pesquisa tomou como base as datas das reuniões do Copom. De um lado, essa opção permite uma estimação da função de reação da autoridade monetária com um retrato mais nítido do seu conjunto de informação. Por outro lado, permite uma análise mais cuidadosa das decisões de política monetária a partir de 2006, quando as reuniões passaram a ocorrer oito vezes por ano.

Além disso, as taxas de juros reais praticadas parecem ter mudado de patamar a partir de meados de 2007, condizente com os diferentes valores obtidos para a taxa de juros nominal a longo prazo na regra de Taylor.

\section{Referências}

BALBINO, C. E.; COLA, E.; TELES, V. K. A política monetária sob o regime de metas para a inflação. Revista Brasileira de Economia, v. 65, n. 2, p. 113-126, 2011.

BARCELLOS NETO, P. C. F.; PORTUGAL, M. S. Determinants of monetary policy committee decisions: Fraga vs. Meirelles. Porto Alegre: PPGE/UFRGS, 2007. (Texto para discussão, n. 2007/11).

CAETANO, S. M.; SILVA JR, G. E.; CORREA, W, L. R. Abordagem discreta para a dinâmica da taxa Selic-meta. Economia Aplicada, v. 15, n. 2, p. 199-221, 2011.

CARNEIRO, D. D.; WU, T. Contas externas e política monetária. Revista Brasileira Economia, V. 58, n. 3, p. 301-323, 2004.

CLARIDA, R.; GALI, J.; GERTLER, M. Monetary policy rules and macroeconomic stability: evidence and some theory. Quarterly Journal of Economics, n. 115, p. 147-180, 2000.

. Monetary policy rules in practice: some international evidence. European Economic Review, n. 42, p. 1.033-1.067, 1998.

GONÇALVES, C. E. S.; FENOLIO, F. Ciclos eleitorais e política monetária: evidências para o Brasil. Pesquisa e Planejamento Econômico, v. 37, n. 3, p. 465-487, dez. 2007.

HOLLAND, M. Monetary and exchange rate policy in Brazil after inflation targeting. In: ENCONTRO NACIONAL DE ECONOMIA, 22., 2005, Natal, RN. Anais... Natal, RN: Anpec, 2005. Disponível em: <http://www.anpec.org.br/encontro2005/artigos/A05A032.pdf>. Acesso em: 9 out. 2011.

MAGALHÃES, C. M. Regra de Taylor e a resposta da taxa de juros à inflação no Brasil. 2007. Dissertação (Mestrado em Economia) - Universidade de São Paulo, São Paulo, 2007.

MINELLA, A. et al. Inflation targeting in Brazil: constructing credibility under exchange rate volatility. Brasília, DF: Banco Central do Brasil, 2003. (Working Paper Series, n. 77).

MODENESI, A. M. Convenção e rigidez na política monetária: uma estimativa da função de reação do BCB (2000-2007). 2010. Disponível em: < http://www.ie.ufrj.br/datacenterie/pdfs/ seminarios/pesquisa/texto2010.pdf> . Acesso em: 12 out. 2011. 
SALGADO, M. J. S.; GARCIA, M. G. P.; MEDEIROS, M. C. Monetary policy during Brazil's real plan: estimating the central bank's reaction function. Revista Brasileira de Economia, $\mathrm{v}$. 59, n. 1, p. 61-80, 2005.

SOARES, J. J. S.; BARBOSA, F. H. Regra de Taylor no Brasil: 1999-2005. In: ENCONTRO NACIONAL DE ECONOMIA, 34., 2006, Salvador, BA. Anais... Salvador, BA: Anpec, 2006.

SULZBACH, V. N. Política monetária sob o regime de metas para inflação: uma estimativa da função de reação do Banco Central do Brasil (2000-2009). 2009. Monografia (Graduação em Ciências Econômicas) - Faculdade de Ciências Econômicas, Universidade Federal do Rio Grande do Sul, 2009. Disponível em: < http://www.lume.ufrgs.br/bitstream/handle/10183/25373/000739538.pdf?sequence =1 > . Acesso em: 2 out. 2001.

TAYLOR, J. Discretion versus policy rules in practice. Carnegie-Rochester Conference Series on Public Policy, n. 39, p. 195-214, 1993.

\section{Apêndice A}

Esta seção apresenta um teste de robustez, mostrando os resultados encontrados utilizando o hiato do produto pela tendência linear e a taxa de câmbio real deflacionada pelo IPCA. Os resultados não se alteram de forma significativa, apontando para uma forte reação da autoridade monetária às expectativas de inflação, mas com peso significativo também para a atividade econômica.

Tabela 3 - Estimações para 2003-2010. Variável dependente: Taxa Selic (meta)

\begin{tabular}{cccc}
\hline $\begin{array}{c}\text { Variável } \\
\text { explicativa }\end{array}$ & (I) & (II) & (III) \\
\hline Constante & $10.82^{* * *}$ & $11.94^{* * *}$ & $11.70^{* * *}$ \\
& $(15.32)$ & $(14.16)$ & $(13.70)$ \\
Selic (t-1) & $0.91^{* * *}$ & $1.46^{* * *}$ & $1.45^{* * *}$ \\
& $(49.65)$ & $(11.29)$ & $(11.14)$ \\
Selic (t-2) & & $-0.52^{* * *}$ & $-0.51^{* * *}$ \\
& & $(-4.2)$ & $(-4.14)$ \\
Desvio das & & & \\
expectativas & $5.25^{* * *}$ & $3.44^{* * *}$ & $3.33^{* * *}$ \\
& $(8.26)$ & $(3.48)$ & $(3.13)$ \\
Hiato do produto & $0.86^{* * *}$ & $0.52^{*}$ & $0.65^{* *}$ \\
& $(3.55)$ & $(1.73)$ & $(2.02)$ \\
Variação cambial & & & -0.20 \\
& & & $(-0.76)$ \\
R2 & & 0.99 & 0.99 \\
$N$ & 0.99 & 76 & 76 \\
Res. Dev. & 76 & 57.18 & 56.08 \\
Root MSE & 95.82 & 0.36 & 0.36 \\
\hline
\end{tabular}

Fonte: Elaboração própria.

Nota: Estatística t entre parênteses. *, ** $\mathrm{e}^{* * *}$ indicam coeficientes estatisticamente significantes a 10,5 e $1 \%$, respectivamente.

Recebido em: 23/09/2012.

Aceito em: 20/05/2013. 